\title{
Doppler ultrasound for prediction of IUCD- induced heavy menstrual bleeding: a prospective cohort study
}

\author{
Mohamed S. Sweed ${ }^{1 *}$ D, Khaled H. Swidan', Naira S. Ibrahim², Eman A. NasrEIDin ${ }^{3}$ and Ihab A. Gomaa'
}

\begin{abstract}
Background: Previous studies reported changes in the local vasoactive substance production within the endometrium with a subsequent increase in vascularity as a possible mechanism of intrauterine contraceptive device (IUCD)-induced heavy menstrual bleeding. This research investigates the role of power Doppler velocimetries of the uterine arteries, endometrium, and sub-endometrium vascularization as a predictor of IUCD-induced heavy menstrual bleeding.

Results: Endometrium flow index (FI) and vascularization flow index (VFI) significantly increased in both groups: women with heavy menstrual bleeding (group A) and women without heavy menstrual bleeding (group B), with significantly higher increase in group A. Endometrium VFI $\geq 0.18$ had the highest significant diagnostic characteristics in the prediction of heavy menstrual bleeding, followed by sub-endometrium $\mathrm{VI} \geq 3.75$.

Conclusion: The results of this study suggest an increase in uterine blood flow in women with IUCD-induced menorrhagia. Endometrial and sub-endometrial Doppler vascular indices can be used for the prediction of IUCDinduced heavy menstrual bleeding.
\end{abstract}

Keywords: Intrauterine contraceptive device, Heavy menstrual bleeding, Menorrhagia, Doppler ultrasound

\section{Background}

Copper intrauterine contraceptive device (IUCD) is the most commonly used method of long-acting reversible contraception worldwide [1]. The most important copper IUCD-related side effect is increased menstrual bleeding approximately $30-50 \%$, often combined with cramping. The menstrual blood may be excessive to the extent of causing iron deficiency anemia [2]. These changes are responsible for a removal rate of $4-15 \%$ during the first year after IUCD insertion [3].

The effect of the copper IUCD on uterine hemodynamics and its relationship with the pathophysiology of IUCDinduced heavy menstrual bleeding is still not well clarified [4]. By using three-dimensional (3D) Doppler analysis,

\footnotetext{
* Correspondence: drmsweed@med.asu.edu.eg

'Department of Obstetrics and Gynecology, Ain Shams University, Cairo 16646, Egypt

Full list of author information is available at the end of the article
}

only few studies have demonstrated an increase in subendometrial vascularization in women with IUCD-induced heavy menstrual bleeding [5]. Using power Doppler provides the possibility of quantifying vascularization within a given volume of interest.

This study was conducted to assess the role of power Doppler velocimetries of the uterine arteries, endometrium, and sub-endometrium vascularization as a predictor of IUCD-induced heavy menstrual bleeding.

\section{Methods}

This prospective cohort study was conducted during the period from September 2018 till November 2019. The study was approved by the institutional Ethical and Research Committee. One hundred and ten women, candidate for copper T 380 IUCD insertion, were included in the study. Pregnant women, nulligravida, women with a history of heavy menstrual bleeding, history of unexplained amenorrhea,

\section{Springer Open}

(ㅇ The Author(s). 2020 Open Access This article is licensed under a Creative Commons Attribution 4.0 International License, which permits use, sharing, adaptation, distribution and reproduction in any medium or format, as long as you give appropriate credit to the original author(s) and the source, provide a link to the Creative Commons licence, and indicate if changes were made. The images or other third party material in this article are included in the article's Creative Commons licence, unless indicated otherwise in a credit line to the material. If material is not included in the article's Creative Commons licence and your intended use is not permitted by statutory regulation or exceeds the permitted use, you will need to obtain permission directly from the copyright holder. To view a copy of this licence, visit http://creativecommons.org/licenses/by/4.0/. 
congenital or acquired uterine anomalies (e.g., septate uterus, uterine polyp or fibroid), current pelvic inflammatory disease, history of use of oral contraceptives, hormonal medication or IUCD within 3 months before the study, women with a bleeding tendency (e.g., thrombophilia or anticoagulant disorders), and sensitivity to copper were excluded from the study.

\section{Study procedure}

Women included in the study had copper T380 IUCD (Silver Line $380^{\circ}$, PREGNA INTERNATIONAL LTD., India, imported by DKT Egypt LLC-Egypt) insertion at day 5 to day 12 of their menstrual cycles. Doppler ultrasound was done to all women before IUCD insertion using SAMSUNG MEDISON CO, LTD, Korea MODEL H60 or Voluson E6 Expert ultrasound machine (General Electric $^{\circ}$, Fairfield, CT, USA), transvaginal probe 7-9 $\mathrm{MHz}, 2 \mathrm{D}$ color Doppler, and again was repeated after 3 months from insertion. Pulse wave Doppler was applied at a sampling gate of $2 \mathrm{~mm}$ with the angle of insonation at less than 30. Uterine artery pulsatility index (PI) and resistance index (RI) were determined automatically following three similar waveforms (Figs. 1 and 2). The ultrasound machine was switched to 3D mode with power Doppler and was used to measure the endometrium (excluding the IUCD) and sub-endometrial region $(1 \mathrm{~mm}$ parallel to the original defined myometrial-endometrial contour). Vascularization index (VI) measures the ratio of the number of color voxels to the total number of voxels (\%) and represents the presence of blood vessels (vascularity). Flow index (FI) measures the mean power Doppler signal intensity $(0-100)$ and represents the average intensity of blood flow. Vascularization flow index (VFI) is calculated by multiplying VI and FI (0-100) and represents a combination of vascularity and flow intensity (Figs. 3, 4, 5, and 6). Ultrasound examinations were carried out between

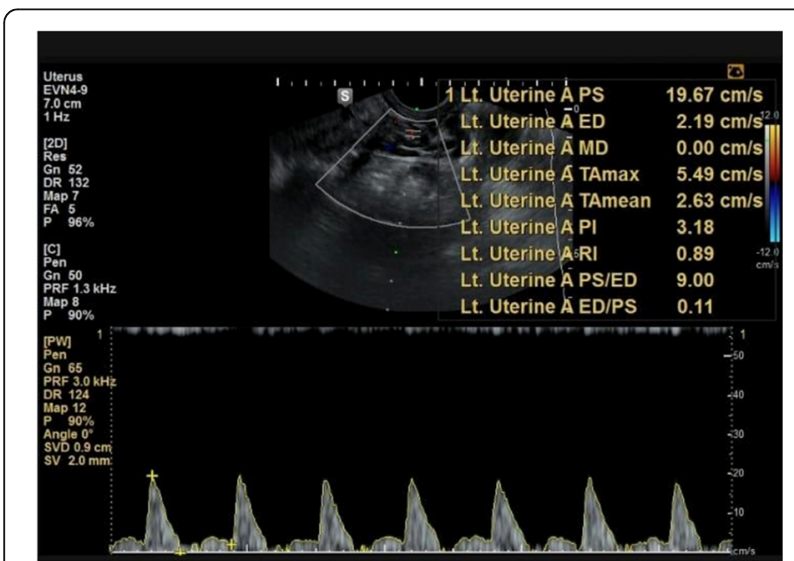

Fig. 1 Transvaginal ultrasonography and color Doppler of the left uterine artery at day 5 of the cycle before insertion of IUCD (Lt. uterine $\mathrm{Pl}=3.18$, Lt. uterine $\mathrm{Rl}=0.89$ )

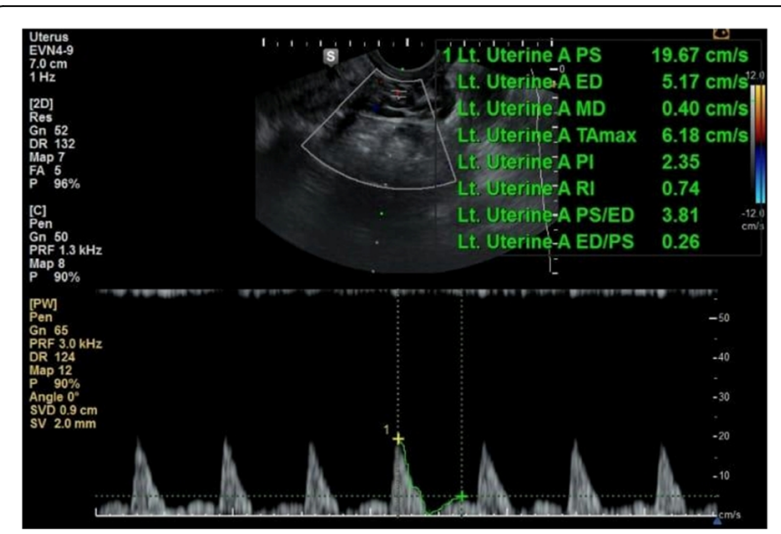

Fig. 2 Transvaginal ultrasonography and color Doppler of the left uterine artery at day 5 of the cycle after insertion of IUCD (Lt. uterine $\mathrm{PI}=2.35$, Lt. uterine $\mathrm{RI}=0.74$ )

days 5 and 12 of the cycle to exclude a possible effect of the menstrual cycle phase and between 9:00 and 10:00 AM to avoid circadian rhythm variation.

Women were assessed before enrollment in the study using pictorial blood assessment system scoring (PBAC) [6] to exclude women with heavy menstrual bleeding, and again, women included in the study were assessed using PBAC where they were either allocated to group A, women with IUCD-induced heavy menstrual bleeding, or group B, women without heavy menstrual bleeding.

Statistical analysis was performed using Stata $^{\circ}$ version 14 (StataCorp LLC, College Station, TX, USA) and XLSTAT@ version 2014.5.03 (Addinsoft, Inc., Brooklyn, NY, USA). Descriptive statistics were done for quantitative data as minimum and maximum of the range as well as mean \pm SD (standard deviation) for quantitative normally distributed data, while it was done for qualitative data as number and percentage. Inferential analyses were done for quantitative variables using the Shapiro-Wilk

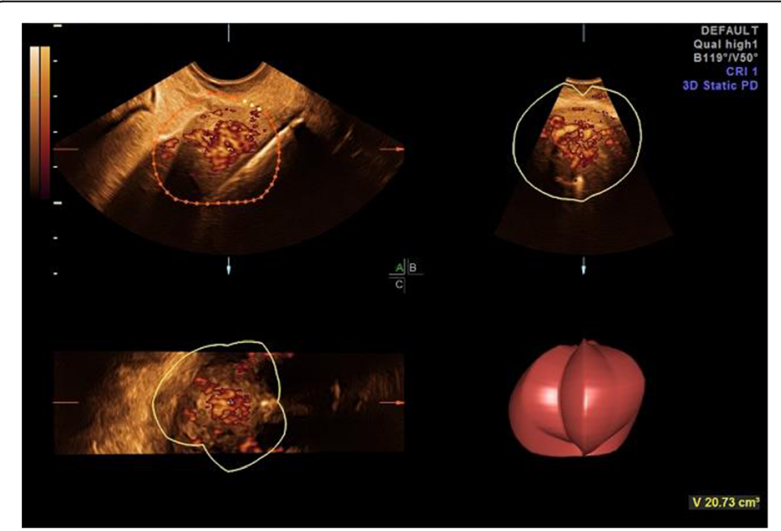

Fig. 3 3D power Doppler of the uterus with IUCD in a case with menorrhagia showing increased sub-endometrium vascularity 


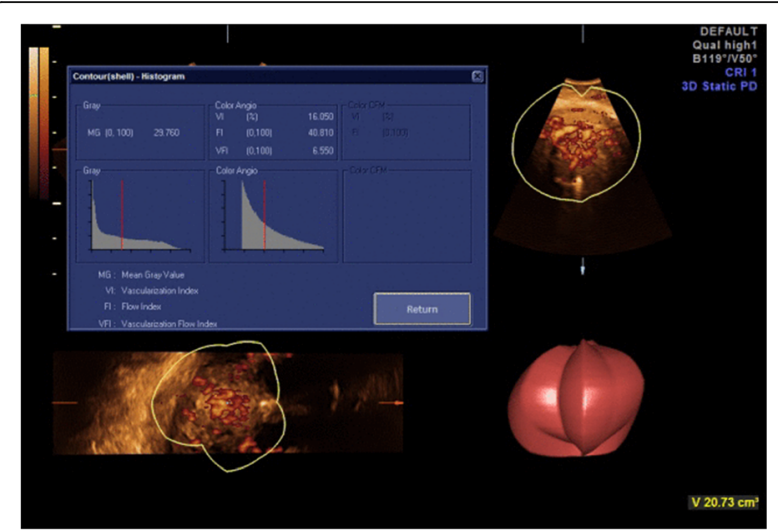

Fig. 4 3D power Doppler indices of the sub-endometrium of a case with menorrhagia $(\mathrm{VI}=16.05, \mathrm{FI}=40.81, \mathrm{VFI}=6.55)$

test for normality testing, independent $t$ test in cases of two independent groups with normally distributed data, and paired $t$ test in cases of two dependent groups. For qualitative data, inferential analyses for independent variables were done using the chi-square test for differences between proportions. ROC curve was used to evaluate the performance of different tests to differentiate between certain groups. The level of significance was taken at $P$ value $<0.05$.

\section{Results}

Out of 158 women assessed for eligibility, 110 women were included in the study (Fig. 7). The mean age of women was $27.6 \pm 3.1(20-35)$ years, mean BMI was $24.2 \pm 1.9 \mathrm{~kg} / \mathrm{m}^{2}$, and median parity was $2(1-3)$. According to the PBAC score, 42 women (38.2\%) developed heavy menstrual bleeding (group A), and the menstrual flow significantly increased after 3 months from IUCD insertion in all the 110 studied women (49.7 \pm 8.5 before,

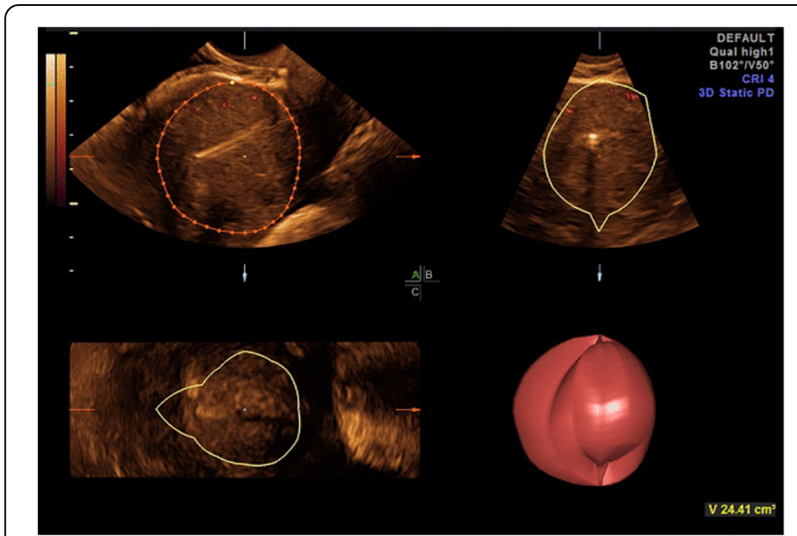

Fig. 5 3D power Doppler of the uterus with IUCD in a case without menorrhagia showing normal sub-endometrium vascularity

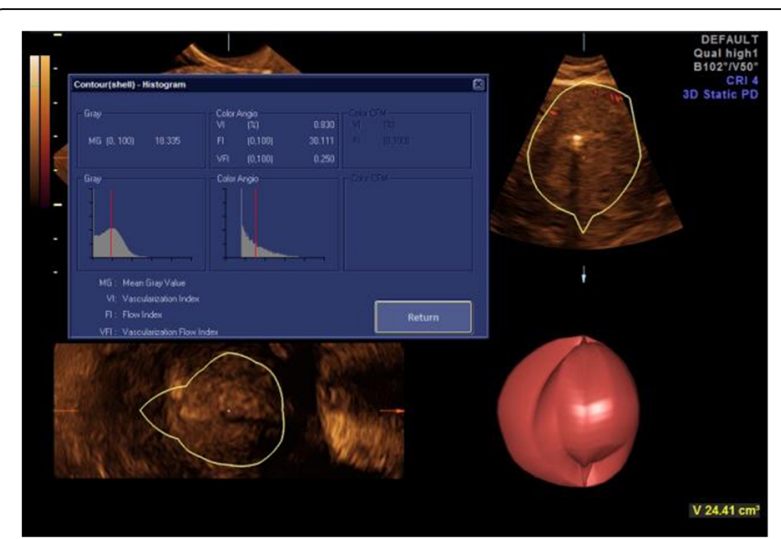

Fig. 6 3D power Doppler indices of the sub-endometrium of a case without menorrhagia $(\mathrm{VI}=0.83, \mathrm{FI}=30.11, \mathrm{VFI}=0.25)$

$100.5 \pm 45.6$ after, $\left.P^{<} 0.001\right)$. The PBAC score was significantly higher in group A than in group B (Table 1). Uterine artery, endometrium, and sub-endometrium vascular indices showed significant change 3 months after IUCD insertion (Table 2). Baseline vascular indices of all, uterine artery, endometrium, and sub-endometrium, differed significantly in women who later developed IUCD-induced menorrhagia from those who did not (Table 3). Endometrium VFI had the highest significant diagnostic performance for the prediction of IUCD-induced heavy menstrual bleeding, followed by sub-endometrium VI (Tables 4 and 5).

\section{Discussion}

An intrauterine contraceptive device (IUCD) is one of the most frequently used methods for birth control around the world. However, menorrhagia is among its side effects. Menorrhagia may cause iron deficiency anemia and usually ends by removing the IUCD in the first year after its insertion in many cases [7].

This prospective cohort study aimed to assess uterine artery, endometrial, and sub-endometrial micro-vascular indices in relation to heavy menstrual bleeding as a predictor of the risk of bleeding before IUCD insertion. Among our studied 110 cases, 42 (38.2\%) developed heavy menstrual bleeding.

Basal PBAC score was comparable between women who later developed heavy menstrual bleeding and those who did not, while in follow-up, the PBAC score was significantly higher in heavy menstrual bleeding cases.

In the current study, uterine artery PI and RI significantly decreased with time in heavy and non-heavy menstrual bleeding cases. Still, uterine artery PI and RI (basal and after 3 months) were significantly lower in heavy menstrual bleeding cases and their reduction was significantly higher in heavy menstrual bleeding cases. 


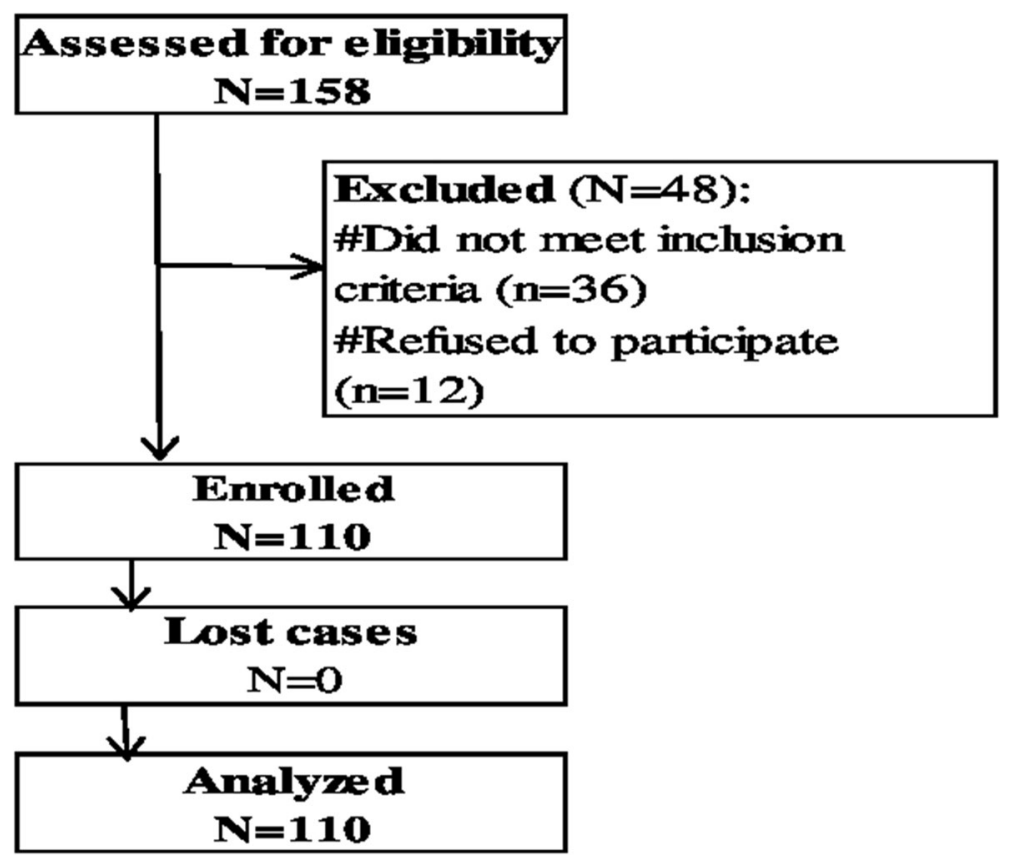

Fig. 7 Flow chart of the study

Several mechanisms have been proposed to explain IUCDinduced menorrhagia: increased endometrial prostaglandins with subsequent increased capillary permeability and vascularity with decreased platelet activity, and also IUCD induces an inflammatory reaction which causes increased nitric oxide production, a potent vasodilator [8]. Other vascular abnormalities due to abnormal angiogenesis have been proposed; abnormal vasculature resulting from abnormal angiogenesis can have poor contractility and hemostatic dysfunction leading to heavy bleeding and decreased uterine artery vascular impedance [9].

Indeed, there is some controversy regarding uterine artery PI and RI in IUCD users. Some studies suggest no difference in RI and PI before and after insertion [10-13], and others demonstrate a PI increase in the midluteal

Table 1 PBAC score in both groups

\begin{tabular}{|c|c|c|c|}
\hline Time & Group A $(N=42)$ & Group B $(N=68)$ & $P$ value \\
\hline \multicolumn{4}{|l|}{ Basal } \\
\hline Mean \pm SD & $51.4 \pm 9.0$ & $48.6 \pm 8.0$ & 0.093 \\
\hline Range & $32.0-67.0$ & $33.0-69.0$ & \\
\hline \multicolumn{4}{|l|}{3 months } \\
\hline Mean \pm SD & $152.8 \pm 28.6$ & $68.1 \pm 10.7$ & $<0.001$ \\
\hline Range & $109.0-201.0$ & $49.0-95.0$ & \\
\hline \multicolumn{4}{|c|}{ \#Change ( 3 months - basal) } \\
\hline Mean \pm SD & $101.4 \pm 30.5$ & $19.5 \pm 6.9$ & $<0.001$ \\
\hline Range & $61.0-163.0$ & $6.0-41.0$ & \\
\hline$P$ value & $<0.001$ & $<0.001$ & \\
\hline
\end{tabular}

phase, yet still agreed with this study and suggested decreased uterine artery PI after IUCD insertion [14]. Some studies reported no statistical difference between women with IUCD-induced heavy menstrual bleeding and those using IUCD with normal menstruation [15, 16]. Still, many studies found uterine artery RI and PI to be much lower in women with IUCD-induced menorrhagia compared to both: women without IUCD-induced menorrhagia and control women [2, 17-20].

Some of the studies reporting no difference in uterine artery vascular indices measured them after a relatively short period from IUCD insertion, only 30 days [10]; this short duration might be insufficient to detect vascular changes by Doppler. This was emphasized in another study which found even increased PI in the participants' first visit, yet was significantly decreased in their second visit especially in women with increased bleeding scores [19].

In the current study, sub-endometrium PI and RI significantly decreased with time in heavy and non-heavy menstrual bleeding cases. Sub-endometrium PI and RI (basal and month 3) were significantly lower in heavy menstrual bleeding cases. On the other hand, sub-endometrium VI, FI, and VFI significantly increased with time in heavy and non-heavy menstrual bleeding cases. Sub-endometrium VI, FI, and VFI (basal and month 3) were significantly higher in heavy menstrual bleeding cases. These results are in agreement with several studies $[5,21]$.

Also, this study showed increased endometrium FI and VFI in both IUCD-induced heavy and non-heavy menstrual bleeding cases which was more evident in women 
Table 2 Uterine artery, endometrium, and sub-endometrium vascular indices

\begin{tabular}{|c|c|c|c|c|c|}
\hline & & Basal & Month 3 & \#Change & $P$ value \\
\hline \multicolumn{6}{|c|}{ Uterine artery } \\
\hline PI & Mean \pm SD & $2.20 \pm 0.63$ & $2.09 \pm 0.61$ & $-0.11 \pm 0.03$ & $<0.001$ \\
\hline RI & Mean \pm SD & $0.85 \pm 0.25$ & $0.81 \pm 0.25$ & $-0.04 \pm 0.01$ & $<0.001$ \\
\hline \multicolumn{6}{|c|}{ Sub-endometrium } \\
\hline PI & Mean \pm SD & $1.72 \pm 0.35$ & $1.63 \pm 0.34$ & $-0.09 \pm 0.03$ & $<0.001$ \\
\hline RI & Mean \pm SD & $0.70 \pm 0.16$ & $0.67 \pm 0.16$ & $-0.03 \pm 0.01$ & $<0.001$ \\
\hline VI & Mean \pm SD & $4.45 \pm 2.39$ & $4.71 \pm 2.59$ & $0.26 \pm 0.21$ & $<0.001$ \\
\hline $\mathrm{FI}$ & Mean \pm SD & $31.47 \pm 5.17$ & $33.11 \pm 5.65$ & $1.64 \pm 0.71$ & $<0.001$ \\
\hline VFI & Mean \pm SD & $1.45 \pm 0.90$ & $1.62 \pm 1.05$ & $0.17 \pm 0.15$ & $<0.001$ \\
\hline \multicolumn{6}{|c|}{ Endometrium } \\
\hline VI & Mean \pm SD & $0.77 \pm 0.34$ & $0.81 \pm 0.37$ & $0.04 \pm 0.03$ & $<0.001$ \\
\hline $\mathrm{FI}$ & Mean \pm SD & $22.61 \pm 6.92$ & $23.81 \pm 7.34$ & $1.21 \pm 0.59$ & $<0.001$ \\
\hline VFI & Mean \pm SD & $0.18 \pm 0.11$ & $0.20 \pm 0.12$ & $0.02 \pm 0.02$ & $<0.001$ \\
\hline
\end{tabular}

with heavy bleeding. These results are in agreement with previous studies examining the effect of copper IUCD on uterine hemodynamic, but disagreed in women without menorrhagia, where there was no significant difference in the endometrial VI, FI, and VFI before and after IUCD insertion $[5,10,12,14,16,22]$. In the current study, endometrium VFI $(\geq 0.18)$ had the highest significant diagnostic performance in the prediction of heavy menstrual bleeding, followed by sub-endometrium VI $(\geq$ 3.75). This higher diagnostic value of endometrium VFI might be explained by several proposed hypotheses for the mechanism of IUCD-induced bleeding. Among these theories, the low-grade endometrial inflammatory reaction associated with increased prostaglandin synthesis and local vascular changes [8].

Table 3 Baseline uterine artery, endometrium, and subendometrium vascular indices

\begin{tabular}{|c|c|c|c|c|c|c|c|c|c|c|}
\hline & & Group A $(N=42)$ & Group B $(N=68)$ & $P$ value & & & & & & \\
\hline Uterin & artery & & & & Table 4 Dia & & & & & \\
\hline PI & Mean \pm SD & $1.77 \pm 0.47$ & $2.46 \pm 0.56$ & $<0.001$ & the predic & 0 & & & & \\
\hline RI & Mean \pm SD & $0.63 \pm 0.16$ & $0.99 \pm 0.20$ & $<0.001$ & Indices & AUC & $\mathrm{SE}$ & $P$ & $95 \% \mathrm{Cl}$ & Cutoff \\
\hline Sub-er & dometrium & & & & Uterine $\mathrm{A}$. PI & 0.816 & 0.040 & $<0.001$ & $0.737-0.894$ & $\leq 2.20$ \\
\hline PI & Mean \pm SD & $1.63 \pm 0.35$ & $1.78 \pm 0.34$ & 0.030 & Uterine A. RI & 0.925 & 0.024 & $<0.001$ & $0.879-0.972$ & $\leq 0.88$ \\
\hline RI & Mean \pm SD & $0.56 \pm 0.12$ & $0.79 \pm 0.11$ & $<0.001$ & Sub-end. PI & 0.602 & 0.054 & 0.073 & $0.495-0.709$ & $\leq 1.94$ \\
\hline VI & Mean \pm SD & $6.87 \pm 1.91$ & $2.96 \pm 1.07$ & $<0.001$ & Sub-end. RI & 0.920 & 0.027 & $<0.001$ & $0.867-0.973$ & $\leq 0.69$ \\
\hline $\mathrm{FI}$ & Mean \pm SD & $33.71 \pm 5.32$ & $30.10 \pm 4.60$ & $<0.001$ & Sub-end. VI & 0.959 & 0.024 & $<0.001$ & $0.895-1.000$ & $\geq 3.75$ \\
\hline VFI & Mean \pm SD & $2.33 \pm 0.80$ & $0.90 \pm 0.39$ & $<0.001$ & Sub-end. FI & 0.707 & 0.054 & $<0.001$ & $0.602-0.813$ & $\geq 3.20$ \\
\hline Endom & letrium & & & & Sub-end. VFI & 0.948 & 0.022 & $<0.001$ & $0.904-0.991$ & $\geq 1.32$ \\
\hline VI & Mean \pm SD & $1.06 \pm 0.32$ & $0.59 \pm 0.20$ & $<0.001$ & End. VI & 0.908 & 0.027 & $<0.001$ & $0.856-0.961$ & $\geq 1.71$ \\
\hline $\mathrm{FI}$ & Mean \pm SD & $24.38 \pm 6.37$ & $21.51 \pm 7.06$ & 0.034 & End. FI & 0.606 & 0.054 & 0.061 & $0.501-0.712$ & $\geq 16.00$ \\
\hline VFI & Mean \pm SD & $0.26 \pm 0.12$ & $0.13 \pm 0.06$ & $<0.001$ & End. VFI & 0.971 & 0.015 & $<0.001$ & $0.940-1.000$ & $\geq 0.18$ \\
\hline
\end{tabular}

Still, it is difficult to attribute the bleeding only to the presence of lower Doppler indices because low PI values can also be detected in patients without IUCD, and PI values lower than 2 can be detected at various phases of the menstrual cycle as well. Nevertheless, PI values lower than 2 detected at the early phase of the menstrual cycle raise the possibility of an increased bleeding risk. Adding 3D Doppler indices with the suggested cutoff values of both endometrium VFI $(\geq 0.18)$ and sub-endometrium VI $(\geq 3.75)$ might increase the predictability of women liable to IUCD-induced heavy menstrual bleeding. Still, the relatively small number of participants included in this study and the 3-month follow-up might be considered limitations of this study; accordingly, further studies with larger sample size and with longer duration of followup, as some cases develop menorrhagia after a longer duration, are needed to further validate this predictive value and its possible clinical application. Also, other studies 
Table 5 Diagnostic characteristics of basal Doppler findings' cutoff points for the prediction of IUCD-induced heavy menstrual bleeding

\begin{tabular}{|c|c|c|c|c|c|}
\hline & $\begin{array}{l}\text { Uterine A. Pl, } \\
\text { cutoff } \leq \mathbf{2 . 2 0}\end{array}$ & $\begin{array}{l}\text { Uterine A. RI, } \\
\text { cutoff } \leq 0.88\end{array}$ & $\begin{array}{l}\text { Sub-end. PI, } \\
\text { cutoff } \leq 1.94\end{array}$ & $\begin{array}{l}\text { Sub-end. Rl, } \\
\text { cutoff } \leq 0.69\end{array}$ & $\begin{array}{l}\text { Sub-end. VI, } \\
\text { cutoff } \geq 3.75\end{array}$ \\
\hline Sensitivity & $88.1 \%$ & $97.6 \%$ & $88.1 \%$ & $85.7 \%$ & $97.6 \%$ \\
\hline Specificity & $60.3 \%$ & $69.1 \%$ & $36.8 \%$ & $80.9 \%$ & $82.4 \%$ \\
\hline DA & $70.9 \%$ & $80.0 \%$ & $56.4 \%$ & $82.7 \%$ & $88.2 \%$ \\
\hline Youden's index & $48.4 \%$ & $66.7 \%$ & $24.9 \%$ & $66.6 \%$ & $80.0 \%$ \\
\hline PPV & $57.8 \%$ & $66.1 \%$ & $46.3 \%$ & $73.5 \%$ & $77.4 \%$ \\
\hline NPV & $89.1 \%$ & $97.9 \%$ & $83.3 \%$ & $90.2 \%$ & $98.2 \%$ \\
\hline LR+ & 2.22 & 3.16 & 1.39 & 4.48 & 5.53 \\
\hline LR- & 0.20 & 0.03 & 0.32 & 0.18 & 0.03 \\
\hline \multirow[t]{2}{*}{ LR } & 11.24 & 91.76 & 4.30 & 25.38 & 191.33 \\
\hline & $\begin{array}{l}\text { Sub-end. Fl, } \\
\text { cutoff } \geq 3.20\end{array}$ & $\begin{array}{l}\text { Sub-end. VFI, } \\
\text { cutoff } \geq 1.32\end{array}$ & $\begin{array}{l}\text { End. VI, } \\
\text { cutoff } \geq 1.71\end{array}$ & $\begin{array}{l}\text { End. FI, } \\
\text { cutoff } \geq 16.00\end{array}$ & $\begin{array}{l}\text { End. VFI, } \\
\text { cutoff } \geq 0.18\end{array}$ \\
\hline Sensitivity & $76.2 \%$ & $97.6 \%$ & $100.0 \%$ & $97.6 \%$ & $95.2 \%$ \\
\hline Specificity & $72.1 \%$ & $75.0 \%$ & $73.5 \%$ & $26.5 \%$ & $86.8 \%$ \\
\hline DA & $73.6 \%$ & $83.6 \%$ & $83.6 \%$ & $53.6 \%$ & $90.0 \%$ \\
\hline Youden's index & $48.2 \%$ & $72.6 \%$ & $73.5 \%$ & $24.1 \%$ & $82.0 \%$ \\
\hline PPV & $62.7 \%$ & $70.7 \%$ & $70.0 \%$ & $45.1 \%$ & $81.6 \%$ \\
\hline NPV & $83.1 \%$ & $98.1 \%$ & $100.0 \%$ & $94.7 \%$ & $96.7 \%$ \\
\hline LR+ & 2.73 & 3.90 & 3.78 & 1.33 & 7.20 \\
\hline LR- & 0.33 & 0.03 & 0.00 & 0.09 & 0.05 \\
\hline LR & 8.25 & 123.00 & $>100.0$ & 14.76 & 131.11 \\
\hline
\end{tabular}

Cl confidence interval, $D A$ diagnostic accuracy, $P P V$ positive predictive value, $N P V$ negative predictive value, $L R+$ positive likelihood ratio, $L R-$ negative likelihood ratio, $L R$ diagnostic odds ratio

might investigate the value of uterine arteries and endometrial Doppler blood flow in IUCD-associated pain.

\section{Conclusion}

The results of this study confirm the hypothesis of increased uterine blood flow in women with IUCDinduced abnormal uterine bleeding. Endometrium and sub-endometrial vascularity is markedly increased in women with IUCD-induced menorrhagia. Endometrial and sub-endometrial Doppler vascular indices can be used for the prediction of IUCD-induced heavy menstrual bleeding.

\section{Abbreviations}

IUCD: Intrauterine contraceptive device; 3D: Three dimensional; PI: Pulsatility index; Rl: Resistance index; VI: Vascularization index; Fl: Flow index; VFI: Vascularization flow index; PBAC: Pictorial blood assessment system scoring; AUC: Area under the curve

\section{Acknowledgements}

Ain Shams University.

\section{Authors' contributions}

MS helped design the study, supervised the undertaking of the trial, undertook the analysis, edited the final manuscript, and shared in funding the study. KS helped design the study, supervised the undertaking of the trial, undertook the analysis, wrote the first draft of the manuscript, and shared in funding the study. NI helped design the study, shared in the undertaking of the trial, assisted with the data analysis, gave editorial feedback to versions of the manuscript, and shared in funding the study. EN shared in the undertaking of the trial, provided advice during the running of the trial, collected data for analysis, gave editorial feedback to versions of the manuscript, and shared in funding the study. All authors read and approved the final manuscript. IG provided detailed statistical advice during the design, supervised the undertaking of the trial, gave editorial feedback to versions of the manuscript, and shared in funding the study.

Funding

The authors did not receive any external funding for the study.

\section{Availability of data and materials}

The datasets used and/or analyzed during the current study are available from the corresponding author on reasonable request.

\section{Ethics approval and consent to participate}

This study was approved by the ethics committee of Ain Shams University with approval number AS1851. The participants provided written consent.

\section{Consent for publication}

All patients included in this research gave written informed consent to publish the data contained within this study.

\section{Competing interests}

The authors declare that they have no competing interests.

\section{Author details}

${ }^{1}$ Department of Obstetrics and Gynecology, Ain Shams University, Cairo

16646, Egypt. ${ }^{2}$ Department of Obstetrics and Gynecology, New Cairo 
Hospital, Cairo, Egypt. ${ }^{3}$ Department of Radiology, Helwan University, Cairo, Egypt.

Received: 6 July 2020 Accepted: 27 October 2020

Published online: 16 November 2020

\section{References}

1. Madden T (2020) In: Post TW, Schreiber CA, Eckler K (eds) Intrauterine contraception: background and device types. UpToDate, Waltham http:// www.uptodate.com

2. Fouda UM, Yossef D, Gaafar HM (2010) Uterine artery blood flow in patients with copper intrauterine device-induced abnormal uterine bleeding. Middle East Fertil Soc J 15(3):168-173

3. Kaneshiro B, Aeby T (2010) Long-term safety, efficacy, and patient acceptability of the intrauterine Copper T-380A contraceptive device. Int J Womens Health 2:211-220

4. Hill MJ, Levens ED, Decherney AH (2012) ACOG Practice Bulletin. Diagnosis of abnormal uterine bleeding in reproductive-aged women. Obstet Gynecol 120(1):197-206

5. El-Mazny A, Abou-Salem N, Elshenoufy H (2013) Three-dimensional power Doppler study of endometrial and subendometrial microvascularization in women with intrauterine device-induced menorrhagia. Fertil Steril 99(7): 1912-1915

6. Magnay JL, O'Brien S, Gerlinger C, Seitz C (2020) Pictorial methods to assess heavy menstrual bleeding in research and clinical practice: a systematic literature review. BMC Womens Health 20:24

7. Sammour HM, Ashoush SA, Ibrahim OI, Ismail YE (2020) Assessment of the efficacy of uterine artery Doppler in predicting the response to Mefenamic acid during treatment of women having IUCD associated menorrhagia. EBWHJ 10(1):104-111

8. Shabaa BA, Al-Jarrah DM, Al-lbrahimi N (2015) Doppler study of the uterine artery in patients with copper intrauterine contraceptive device-induced abnormal uterine bleeding. J Kerbala Univ 13(3):111-117

9. Mints M, Blomgren B, Palmblad J (2007) Expression of vascular endothelial growth factor receptor-3 in the endometrium in menorrhagia. Int J Mol Med 19(6):909-913

10. de Souza MA, Geber S (2006) Doppler color flow analysis of the uterine arteries before and after intrauterine device insertion: a prospective study. J Ultrasound Med 25(2):153-157

11. Pakarinen $P$, Luukkainen $T$, Laine $H$, Lähteenmäki $P$ (1995) The effect of local intrauterine levonorgestrel administration on endometrial thickness and uterine blood circulation. Hum Reprod 10(9):2390-2394

12. Shen O, Chetrit AB, Margalioth EJ, Lavie O, Rabinowitz RR (2008) Effects of a copper-medicated intrauterine device on ovarian artery, uterine artery, and intrauterine blood flow. Gynecol Obstet Invest 66(4):253-256

13. Mutlu I, Demir A, Mutlu MF (2014) Can uterine artery Doppler parameters predict copper intrauterine device-induced side effects? Eur J Contracept Reprod Health Care 19(1):51-56

14. Järvelä I, Tekay A, Jouppila P (1998) The effect of a levonorgestrel-releasing intrauterine system on uterine artery blood flow, hormone concentrations and ovarian cyst formation in fertile women. Hum Reprod 13(12):3379-3383

15. Jiménez MF, Passos EP, Fagundes PA, de Freitas FM, Arbo E, Cunha-Filho JS (2006) Effect of the copper-intrauterine device (TCu 380A) on subendometrial microvascularization and uterine artery blood flow. Fertil Steril 86(6):1780-1782

16. Jiménez MF, Arbo E, Vetori D, de Freitas FM, Cunha-Filho JS (2008) The effect of the levonorgestrel-releasing intrauterine system and the copper intrauterine device on subendometrial microvascularization and uterine artery blood flow. Fertil Steril 90(5):1574-1578

17. Momtaz M, Zayed M, Rashid K, Idriss O (1994) Doppler study of the uterine artery in patients using an intrauterine contraceptive device. Ultrasound Obstet Gynecol 4(3):231-234

18. Frajndlich R, Corleta H, Frantz N (2000) Color Doppler sonographic study of the uterine artery in patients using intrauterine contraceptive devices. J Ultrasound Med 19(8):577-579

19. Yigit N, Kacar M, Yigit H, Kosar P, Kosar U (2009) The effects of copper contraceptive intrauterine device on the uterine blood flow: a prospective transvaginal Doppler study. J Clin Ultrasound 37(7):380-384

20. Mohamed RS, AbdelHakim SF (2015) Uterine artery Doppler as predictor of side effects in copper intrauterine device users. Al-Azhar Assiut Med J 13(4):63-71
21. Mansour G, Hussein S, Mohammed H, Mekkawy S, Akl S, Dayem A (2017) Can we predict menorrhagia with intrauterine contraceptive device (IUCD) insertion? Open J Obstet Gynecol 7(7):753-766

22. Zalel Y, Shulman A, Lidor A, Achiron R, Mashiach S, Gamzu R (2002) The local progestational effect of the levonorgestrel-releasing intrauterine system: a sonographic and Doppler flow study. Hum Reprod 17(11):2878-2880

\section{Publisher's Note}

Springer Nature remains neutral with regard to jurisdictional claims in published maps and institutional affiliations.

\section{Submit your manuscript to a SpringerOpen ${ }^{\circ}$ journal and benefit from:}

- Convenient online submission

- Rigorous peer review

- Open access: articles freely available online

- High visibility within the field

- Retaining the copyright to your article

Submit your next manuscript at $\boldsymbol{\nabla}$ springeropen.com 